\title{
Socio-Demogrphic Profile and Complications of Patients with Retained Placenta in a Tertiary Centre, South-South Nigeria
}

\author{
Christopher U. Iklaki, Cajethan I. Emechebe*, Charles O. Njoku, Boniface U. Ago, \\ Brown S. Ugwu \\ Department of Obstetrics and Gynaecology, University of Calabar Teaching Hospital (UCTH), Calabar, Nigeria \\ Email: *Newlifecj@yahoo.com
}

Received 11 January 2016; accepted 26 January 2016; published 29 January 2016

Copyright (C) 2016 by authors and OALib.

This work is licensed under the Creative Commons Attribution International License (CC BY). http://creativecommons.org/licenses/by/4.0/

(c) (i) Open Access

\section{Abstract}

Retained placenta is a life threatening emergency and a major cause of primary postpartum haemorrhage and maternal morbidity in the developing world. Objectives: To determine the sociodemographic characteristics and complications in patients presenting with retained placenta in this centre. Materials and Method: This was a retrospective study of all cases of retained placenta managed at the UCTH from January 1 st 2008 to December 31st 2012. The case records of these patients were retrieved and analysed using Epi info 3.3.2. Results: There were 138 patients with retained placenta during the period, giving an incidence of $1.02 \%$. The mean age was $27.7 \pm 4.6$ years with a range of $17-41$ years. Majority of the cases of retained placenta occurred in the age group of 26 - 30 years (37\%); para $4(36.1 \%)$; traders $(48.7 \%)$ and unbooked $(68.1 \%)$. Most patients delivered outside the hospital by unskilled birth attendants at churches, traditional birth attendants and patient's home $(69.0 \%)$. Eleven $(9.2 \%)$ patients had previous caesarean sections while $7(5.9 \%)$ had placenta retention in the past. The complications observed were mostly primary postpartum haemorrhage $67(56.3 \%)$ and anaemia $79(66.4)$. Unbooked patients significantly had more primary postpartum haemorrhage $(\mathrm{P}$-value $=\mathbf{0 . 0 3 2 5})$ and anaemia $(\mathrm{P}$-value $=$ $0.0000)$ than the booked patients. Nineteen $(16.0 \%)$ patients presented in shock out of which 1 died due to severe haemorrhagic shock, giving a case fatality rate of $0.8 \%$. Conclusion: Poorly managed labour and delivery is the major cause of retained placenta. Therefore, supervised hospital delivery is paramount to reduce the observed complications.

\section{Keywords}

Retained Placenta, Anaemia, Postpartum Haemorrhage, Maternal Morbidity, Caesarean Section

Subject Areas: Gynecology \& Obstetrics

\footnotetext{
${ }^{*}$ Corresponding author.

How to cite this paper: Iklaki, C.U., Emechebe, C.I., Njoku, C.O., Ago, B.U. and Ugwu, B.S. (2016) Socio-Demogrphic Profile and Complications of Patients with Retained Placenta in a Tertiary Centre, South-South Nigeria. Open Access Library Journal, 3: e2364. http://dx.doi.org/10.4236/oalib.1102364
} 


\section{Introduction}

Retained placenta is a life-threatening condition and a major cause of postpartum haemorrhage (PPH), hence a significant factor in maternal morbidity and mortality [1]-[4]. It is generally defined as failure of delivery of the placenta within 30 minutes after childbirth [3] [6], however, some authorities accept a time limit of 60 minutes [4]. With the traditional or expectant management, the placenta usually delivers within 10 - 20 minutes, while with active management; it is commonly delivered within 5 - 10 minutes [4]. Generally, 90\% of placenta will be delivered within 15 minutes, and $96 \%$ within 30 minutes [4].

Retained placenta affects between $0.5 \%$ - 3.3\% of women following normal vaginal deliveries depending on the population studied [1] [3]. There is considerable variation in the retained placenta rates between countries. The overall risk in the general population has been estimated to be about $2.1 \%$ and where this had occurred before, the risk of repetition is said to be 2 - 4 times the risk of those patients without any such previous history [5] [6]. The difference in prevalence is related to the differences in aetiological factors for a prolonged third stage of labour [3].

A common cause of retained placenta is the poor management of third stage of labour [2] [4]. Various risk factors predispose to retained placenta and some of these factors independently affect the third stage of labour. They include multiparity, augmentation of labour with oxytocics, uterine inertia/atony, uterine fibroids and home delivery [7].

Other risk factors that have also been suggested to predispose to retained placenta include induction of labour, prolonged labour, preterm deliveries, previous placental retention, previous dilatation and curettage, previous caesarean section and morbidly adherent placenta [6] [8]-[11].

The gold standard of management of retained placenta is adequate emergency resuscitation and manual removal under anaesthesia to avoid postpartum haemorrhage. Alternative strategies include the use of uterotonic drugs plus controlled cord traction and the use of umbilical vein injection of saline solution plus oxytocin [12] [13]. The non-surgical strategies are very useful especially in rural areas where facilities and skills for manual removal are lacking.

Majority of cases are treated by manual removal under general anaesthesia [3]-[5] [11]. The timing of the procedure depends on the availability of safe anaesthesia and also on the presence or absence of haemorrhage. The time allowed to elapse varies, and many authorities suggest a delay of 30 - 60 minutes in the absence of haemorrhage. This is because there is no increase in haemorrhage until at least 30 minutes post-partum and because of the finding that between 30 and 60 minutes a further $40 \%$ of placentas will spontaneously deliver with the loss of an average of only $300 \mathrm{ml}$ of blood [12] [14].

Regarding the morbidities of retained placenta, haemorrhage, anaemia and hypovolaemic shock are common occurrences [13]. Other complications are acute renal injury, anaesthetic complications, genital tract laceration, hysterectomy, uterine inversion, uterine sub-involution, puerperal sepsis following manual removal and maternal death. Coagulation disorders with massive blood loss are lethal factors in this condition [13] [15] [16].

The most important prophylactic measure to prevent retained placenta is the active management of the third stage of labour [3] [16] [17].

There was a need to identify the risk factors of retained placenta and mode of presentation prevalent in our area with a view to making recommendations on the measures to reduce the incidence and associated complications. This study was therefore aimed to evaluate the socio-demographic characteristics and complications in patients presenting with retained placenta in our centre.

\section{Materials and Methods}

This is a retrospective cross-sectional study of all patients with retained placenta seen at the University of Calabar Teaching Hospital over a period of 5 years spanning from January 1st 2008 to December 31st 2012. The University of Calabar Teaching Hospital is a tertiary health care institution in Calabar Cross-River State, Southsouth geopolitical zone of Nigeria, with referrals of patients from primary and secondary health care facilities, private hospitals and maternity homes. Some other group of patients are from traditional birth attendant homes and churches where deliveries are conducted. The research protocol fulfilled the criteria for approval by the research ethics committee of the hospital. The case notes of the patients were retrieved from the Medical Records Department of the hospital and relevant data obtained from them. The labour ward and theatre records were also retrieved and analysed. Out of 138 cases of retained placenta, 119 case files were available and were used for 
analysis. The derived data were analyzed using Epi-info 3.3.2 statistical package and represented by simple percentages and descriptive statistics. A p-value of $<0.05$ at $95 \%$ level of significance was considered statistically significant.

\section{Results}

A total of 138 cases of retained placenta were managed at the maternity unit of the University of Calabar Teaching Hospital over the study period of 5 years. During this period, a total of 13,557 deliveries were recorded giving an incidence of $1.02 \%$ of total delivery.

Table 1 shows the socio-demographic characteristics of the patients. The mean age was $27.7 \pm 4.6$ years with a range of 17 - 41 years. Majority of the cases of retained placenta occurred in the age group of 26 - 30 years (37\%); para 4 (36.1\%); traders (48.7\%) and unbooked patients (68.1\%). The age range of 21 - 35 constitutes 102 (85.7\%). The parity of the patients prior to delivery was between 0 and 7 . The third, fourth and grandmultiparous patients made up the majority of cases (75.6\%), accounting respectively for 15 (12.6\%), 43 (36.1\%) and 32 (26.9\%) cases. A total of 52 (43.70\%) of the patients had secondary education while 43 (33.62\%) had primary levels of education. Eleven (9.24\%) of the patients did not have any formal education. Eighty one (68.1\%) of the patients were unbooked for antenatal care while booked patients accounted for $31.9 \%$ of all the cases.

Table 2 shows that majority of the patients who had retained placenta delivered outside our hospital and only presented with the complications of retained placenta. Fifty six (38.7\%) patients delivered in churches, 27 (22.7\%) delivered at the traditional birth attendants' places, 9 (7.6\%) delivered at their respective homes while only 29 (24.4\%) of the cases delivered in the labour ward of our Hospital over the study period.

\section{Table 1. Socio-demographic characteristics of patients with retained placenta.}

\begin{tabular}{|c|c|c|c|}
\hline DISTRIBUTION & FREQUENCY & PERCENTAGE (\%) & CUMMULATIVE PERCENTAGE \\
\hline \multicolumn{4}{|l|}{ AGE (YEARS) } \\
\hline$\leq 20$ & 10 & 8.4 & 8.4 \\
\hline $21-25$ & 32 & 26.9 & 35.3 \\
\hline $26-30$ & 44 & 37.0 & 72.3 \\
\hline $31-35$ & 26 & 21.8 & 94.1 \\
\hline $36-40$ & 5 & 4.2 & 98.3 \\
\hline$>40$ & 2 & 1.7 & 100.0 \\
\hline \multicolumn{4}{|l|}{ PARITY } \\
\hline 0 & 14 & 11.8 & 11.8 \\
\hline 1 & 10 & 8.4 & 20.2 \\
\hline 2 & 5 & 4.2 & 24.4 \\
\hline 3 & 15 & 12.6 & 37.0 \\
\hline 4 & 43 & 36.1 & 73.1 \\
\hline$\geq 5$ & 32 & 26.9 & 100.0 \\
\hline \multicolumn{4}{|l|}{ OCCUPATION } \\
\hline Traders & 58 & 48.7 & 48.7 \\
\hline House Wives & 18 & 15.1 & 63.8 \\
\hline Farmers & 16 & 13.5 & 77.3 \\
\hline Civil Servants & 14 & 11.8 & 89.1 \\
\hline Students & 11 & 9.2 & 98.3 \\
\hline Unspecified & 2 & 1.7 & 100.0 \\
\hline \multicolumn{4}{|c|}{ EDUCATIONAL STATUS } \\
\hline None & 11 & 9.2 & 9.2 \\
\hline Primary & 43 & 36.1 & 45.3 \\
\hline Secondary & 52 & 43.7 & 89.0 \\
\hline Tertiary & 13 & 10.9 & 100.0 \\
\hline \multicolumn{4}{|l|}{ BOOKING STATUS } \\
\hline Booked & 38 & 31.9 & 31.9 \\
\hline Unbooked & 81 & 68.1 & 100.0 \\
\hline
\end{tabular}


The relevant clinical features at presentation and risk factors for retained placenta are shown in Table 3 . Among the patients who had active vaginal bleeding from retained placenta, unbooked patient (38.3\%) significantly had active bleeding than booked patient $(15.8 \%)$ over the study period $\left(\mathrm{X}^{2}=4.377\right.$; P-value $\left.=0.0364\right)$. Hypovolemic shock was significantly more among unbooked patients than the booked $\left(\mathrm{X}^{2}=7.3988\right.$; $\mathrm{P}$-value $=$ 0.0065). All booked patient who delivered in the hospital and had retained placenta received prophylactic oxytocics while only 21 (25.9\%) of unbooked who delivered outside UCTH were given prophylactic oxytocics during the third stage of labour. A total of 9 (7.6\%) of the patients with retain placenta had induction of labour, 47 (39.5\%) had prolonged labour that lasted more than 12 hours and 11 (9.2\%) of the patients had previous caesarean sections. Prolonged labour as a risk factor for retained placenta was significantly higher among unbookedwomen than the booked patients $\left(X^{2}=16.2058\right.$; P-value $\left.=0.0001\right)$.

The complications observed were mostly primary postpartum haemorrhage 67 (56.3\%) and anaemia 79 (66.4) as shown in Table 4. Unbooked patients significantly had more primary postpartum haemorrhage $\left(\mathrm{X}^{2}=4.574\right.$; P-value $=0.0325)$ and anaemia $\left(\mathrm{X}^{2}=21.838\right.$; P-value $\left.=0.0000\right)$ than the booked patients. Haemorrhage was severe enough to result in shock in 19 (16.0\%) of cases, out of which one women died due to severe haemorrhagic shock resulting in a case fatality rate of $0.8 \%$. A total of $23(19.3 \%)$ patients stayed for at least 5 days on admission because of the associated complications they were being managed for. Other complications observed in the study included puerperal sepsis 17 (14.3) and a case of acute renal injury (0.8\%), who subsequently had dialysis at the dialysis unit of the hospital.

\section{Discussion}

The incidence of retained placenta of $1.02 \%$ in this study is within the reported incidence of $0.5 \%-3.0 \%$ by

Table 2. Distribution of place of delivery of patients with retained placenta.

\begin{tabular}{ccc}
\hline PLACE OF DELIVERY & FREQUENCY & PERCENTAGE (\%) \\
\hline Home & 9 & 7.6 \\
Church & 46 & 38.7 \\
Primary Health Care & 4 & 3.4 \\
Maternity Home & 4 & 3.4 \\
Traditional Birth Attendant Place & 27 & 22.7 \\
UCTH (Labour ward) & 29 & 24.4 \\
TOTAL & 119 & 100 \\
\hline
\end{tabular}

Table 3. Clinical features and risk factors.

\begin{tabular}{|c|c|c|c|c|c|}
\hline CLINICAL PRESENTATION & TOTAL (\%) & $\begin{array}{c}\text { BOOKED } \\
\text { NUMBER (\%) }\end{array}$ & $\begin{array}{l}\text { UNBOOKED } \\
\text { NUMBER (\%) }\end{array}$ & $\mathbf{X}^{2}$ & P-VALUE \\
\hline Active bleeding & $37(31.1)$ & $6(15.8)$ & $31(38.3)$ & 4.377 & 0.0364 \\
\hline Snapped cord & $21(17.7)$ & $5(13.2)$ & $16(19.8)$ & 0.774 & 0.5789 \\
\hline Shock & $19(16.0)$ & $1(2.6)$ & $18(22.2)$ & 7.3988 & 0.0065 \\
\hline Bulky atonic uterus & $23(19.3)$ & 7 (18.4) & $16(19.8)$ & 0.0294 & 0.8638 \\
\hline Prophylactic oxytocin given & $48(40.3)$ & $27(71.1)$ & $21(25.9)$ & 26.958 & 0.0000 \\
\hline \multicolumn{6}{|l|}{ RISK FACTORS } \\
\hline Induction of labour & $9(10.9)$ & $9(23.7)$ & - & - & - \\
\hline Prolonged labour & $47(39.5)$ & $5(13.2)$ & $42(51.9)$ & 16.2058 & 0.0001 \\
\hline Previous caesarean section & $11(9.2)$ & $8(21.1)$ & $3(3.7)$ & 9.2799 & 0.0023 \\
\hline Previous myomectomy & $4(3.4)$ & $3(7.9)$ & $1(1.2)$ & 3.532 & 0.0602 \\
\hline History of induced abortion & $68(57.2)$ & $21(55.3)$ & $47(58.0)$ & 0.0805 & 0.7766 \\
\hline Uterine fibroid in pregnancy & $6(5.0)$ & $2(5.3)$ & $4(4.9)$ & 0.0057 & 0.9398 \\
\hline Preterm (GA less than 37 weeks) & $11(9.2)$ & $5(13.2)$ & $6(7.4)$ & 1.0195 & 0.3126 \\
\hline Placenta accreta & $1(0.8)$ & $0(0.00)$ & $1(1.2)$ & 0.473 & 0.4916 \\
\hline Previous retained placenta & $7(5.9)$ & $4(10.5)$ & 3 (3.7) & 2.1747 & 0.1403 \\
\hline
\end{tabular}


Table 4. Complications of retained placenta.

\begin{tabular}{|cccccc}
\hline COMPLICATIONS & TOTAL (\%) & $\begin{array}{c}\text { BOOKED (38) } \\
\text { Number (\%) }\end{array}$ & $\begin{array}{c}\text { UNBOOKED (81) } \\
\text { Number (\%) }\end{array}$ & X $^{2}$ & P-VALUE \\
\hline Primary postpartum haemorrhage & $67(56.3)$ & $16(42.1)$ & $51(63.0)$ & 4.574 & 0.0325 \\
Anaemia (haematocrit $<30 \%)$ & $79(66.4)$ & $14(36.4)$ & $65(80.3)$ & 21.838 & 0.0000 \\
• Severe $(\leq 18 \%)$ & $11(9.2)$ & $0(0.00)$ & $11(13.6)$ & 5.6861 & 0.0171 \\
• Moderate (19\% - 26\%) & $27(22.7)$ & $3(7.9)$ & $24(29.6)$ & 0.9659 & 0.0083 \\
• Mild (27\% - <30\%) & $41(34.5)$ & $11(28.9)$ & $30(37.0)$ & 0.7495 & 0.3866 \\
Hypovolemic shock & $19(16.0)$ & $1(2.6)$ & $18(22.2)$ & 7.3988 & 0.0065 \\
Puerperal sepsis/Endometritis & $17(14.3)$ & $2(5.3)$ & $15(18.5)$ & 3.7115 & 0.0540 \\
Acute renal failure & $1(0.8)$ & $0(0.00)$ & $1(1.2)$ & 0.4731 & 0.4916 \\
Maternal mortality & $1(0.8)$ & $0(0.00)$ & $1(1.2)$ & 0.4731 & 0.4916 \\
Secondary postpartum haemorrhage & $16(13.5)$ & $2(5.3)$ & $14(17.3)$ & 3.2116 & 0.0731 \\
Prolonged hospital stay ( $\geq$ 5days) & $23(19.3)$ & $4(10.5)$ & $19(23.5)$ & 2.7736 & 0.0958 \\
\hline
\end{tabular}

several authors in most hospitals in Nigeria and elsewhere [1] [6]-[9]. An incidence of $0.8 \%$ was reported in Jos North-Central Nigeria [18], while a relatively lower incidence of $0.6 \%$ was reported in Saudi Arabia [8]. This slight difference may be due to the difference in the number of unbooked pregnant women who delivered outside the hospital unsupervised and subsequently present to the hospital with complications of retained placenta. The incidence is likely to be lower in areas where pregnant women utilised the available antenatal care facilities and subsequently had skilled care in labour.

There was a preponderance of retained placenta among patients within the age range of 21 - 35 years who constituted $85.7 \%$ of the patients. Similarly, high figures of $76.9 \%, 71.2 \%$ and $89.1 \%$ were recorded for the same age range of 21 - 35 years in Thailand [15], Saudi Arabia [8] and Nigeria [16] respectively. This relationship to age may be a reflection of the reproductive age group of the study population [19]. The age group of 21 35 years is in fact the peak age of child bearing when most women are likely to be pregnant and deliver and hence, the observed finding.

A greater percentage of the patients in this study (75.6\%) were of parities 3 and above. This is congruent with figures of studies from Jos [18] and Ile Ife, Nigeria [6]. Repeated pregnancy and delivery is a risk factor implicated in retained placenta [20]. The reason is due to increased fibrous tissues from repeated deliveries which reduces the contractile power of the uterus and this may lead to uterine atony and therefore placental retention. In Nigeria with heterogeneous population and low utilisation of contraceptive [21], the problem of high parity still exists. This finding in multiparous women in our environment coupled with unbooked status may have increased the incidence of retained placenta in this study.

Majority of the patients with retained placenta were of low educational status as only $10.9 \%$ had tertiary education while $36.1 \%$ had primary education and $9.2 \%$ have no formal education. This finding is comparable to the report in Ibadan where only $17 \%$ of the patients in that study had tertiary education [9]. This is a clear reflection of low educational background among majority of the patients with retained placenta. This observation is not unusual as formal education is likely to enhance women knowledge, attitude and practice toward utilisation of health care facility during pregnancy and delivery with subsequent reduction in pregnancy complications.

Majority of the patients (68.1\%) were unbooked for antenatal care. This is similar to the study in Ibadan where $62.2 \%$ of the study population were unbooked for antenatal care [9]. In most sub-Saharan African countries, utilization of antenatal care is still low and unbooked patients are more likely to be supervised by unskilled birth attendants and hence at risk of delayed or poor management of the third stage of labour [6]. A Nigerian study carried out in Ile Ife also demonstrated that non-booking for antenatal care constitutes an approximately 23 fold increase in the risk of retained placenta [6]. Majority of the patients delivered outside the hospital while only $24.4 \%$ of the cases delivered in the labour ward of our hospital. Most of the patients delivered in churches (38.7\%), traditional birth attendants' places (22.7\%). These unskilled birth attendants usually manage the third stage of labour wrongly and usually do not refer these cases at the appropriate time until serious complications arise.

Induction of labour contributed $10.9 \%$ of cases of retained placenta in this study. Induction of labour contributed $10.3 \%$ to the incidence of retained placenta in a Saudi Arabian study [22]. Placental retention may be the 
result of uterine atony caused by uterine muscle exhaustion sometimes encountered in cases of induced and oxytocin-augmented labours [23].

Sixty eight (57.2\%) patients had previous dilatation and curettage,9.2\% of the patients had previous caesarean sections while $3.4 \%$ patients had a previous myomectomy. Caesarean section, dilatation and curettage and myomectomy for uterine fibroids are procedures which can inadvertently cause endometrial injury facilitating the infiltration of the uterine muscles by the chorionic villi due to deficient or damaged endometrium at such site. This may account for placenta accreta often encountered in cases of retained placenta as was recorded in this study where $0.8 \%$ of placenta accrete was observed.

The major complication in this study was primary postpartum haemorrhage, which occurred in $56.3 \%$ of the cases. It was also a common complication observed in studies in developing countries [6] [7] [9]. A lower incidence was observed in a similar study in Aberdeen, where postpartum haemorrhage was reported in $21.3 \%$ of women with retained placenta [24]. This disparity may be due to the relatively higher rate of out-of-hospital deliveries and unbooked pregnancy in developing countries [19]. The common clinical features observed in this study were active vaginal bleeding, anaemia and shock. Seventy nine (66.4\%) of patients in this study were anaemic with packed cell volumes of less than $30 \%$. Haemorrhage was severe enough to warrant blood transfusion in 33 (27.7\%) of patients in the study population. This finding is similar to some studies in Nigeria [9] [16] [18]. However, only $10 \%$ of the retained placenta group in a large Norwegian cohort study were transfused [25]. This may be due to the relatively higher number of hospital deliveries in the developed countries, with timely intervention that reduces the risk of primary postpartum haemorrhage and hence a huge reduction in the need for blood transfusion.

One patient died of severe haemorrhagic shock resulting in a case fatality rate of $0.8 \%$. The patient was an unbooked woman who presented in a state of irreversible shock secondary to massive haemorrhage following unsupervised home delivery. Two cases of maternal mortalities were recorded in similar studies in Ibadan resulting in case fatalities of $2.2 \%$ [9]. The patients were unbooked, and died from severe haemorrhagic shock following home deliveries. The mortality rate in this study was lower than the outcome in a study carried out in Zaria, Nigeria, where the mortality was 3\% amongst 894 women treated for retained placenta [26].

\section{Conclusion}

Retained placenta still remains a potentially life-threatening condition and one of the major obstetric problems in our environment. Our study revealed that the majority of the cases of retained placenta occurred in the age group of 26 - 30 years; para 4 and unbooked. Most patients delivered outside the hospital attended by unskilled birth attendants. The common risk factors observed were previous history of induced abortion, prolonged labour, induction of labour, preterm delivery and previous caesarean sections. The common complications were high rate of postpartum haemorrhage, anaemia with multiple blood transfusion and puerperal infections, which are also the significant factors responsible for high maternal morbidity and mortality in developing country. Therefore, improvements in the quality of obstetric care available in our country and the utilization by our pregnant women, through enhanced education, booking for antenatal care and economic empowerment of women will go a long way in reducing the complications in our society. Skilled care in labour and provision of emergency obstetric care services that are accessible and affordable will help a lot in reducing the incidence of retained placenta and the observed complications.

\section{Conflict of Interests}

The authors declare that there is no conflict of interests regarding the publication of this paper.

\section{References}

[1] Cheung, W.M., Hawkes, A., Ibish, S. and Weeks, A.D. (2011) The Retained Placenta: Historical and Geographical Rate Variations. Journal of Obstetrics and Gynaecology, 31, 37. http://dx.doi.org/10.3109/01443615.2010.531301

[2] Poggi, S.B.H. (2007) Postpartum Haemorrhage and the Abnormal Puerperium. In: Decherny, A.H., Goodwin, T.M., Laufer, N. and Nathan, L., Eds., Current Obstetric and Gynaecologic Diagnosis and Treatment, 10th Edition, Lange Medical Books, McGraw-Hill, California, Vol. 31, 477-497.

[3] Andrews, D.W. (2008) The Retained Placenta. Best Practice and Research Clinical Obstetrics and Gynaecology, 22, 
1103-1117. http://dx.doi.org/10.1016/j.bpobgyn.2008.07.005

[4] Baskett, F.T., Calder, A.A. and Arulkumaran, S. (2007) Retained Placenta. In: Munro Kerr's Operative Obstetrics, 11th Edition, Sanders Elsevier, London, Vol. 19, 237-241.

[5] World Health Organisation (2005) The World Report 2005. Attending to 136 Million Births Every Year 2005. Make Every Mother and Child Count. The World Health Organisation, Geneva, 62-63.

[6] Owolabi, A.T., Dare, F.O., Fasubaa, O.B., Ogunlola, I.O., Kuti, O. and Bisiriyu, L.A. (2008) Risk Factors of Retained Placenta in Southwest Nigeria. Singapore Med, 49, 532.

[7] Rizwan, N., Abbasi, R.M. and Jatoi, N. (2009) Retained Placenta Still a Cause of Maternal Morbidity and Mortality. Journal Pakistan Medical Association, 59.

[8] Adelusi, B., Soltan, M.H., Chowdhury, N. and Kangave, D. (1997) Risk of Retained Placenta: Multivariate Approach. Acta Obstetricia et Gynecologica Scandinavica, 76, 414-418. http://dx.doi.org/10.3109/00016349709047821

[9] Obajimi, G.O., Roberts, A.O., Aimakhu, C.O., Bello, F.A. and Olayemi, O. (2009) An Appraisal of Retained Placenta in Ibadan: A Five-Year Review. Annals of Ibadan Postgraduate Medicine, 7.

[10] Donnette, S.S., Thame, M., Aleith, H.K., Hambleton, I. and Serjeant, G.R. (2009) Retained Placenta in Homozygous Sickle Cell Disease. Obstetrics \& Gynecology, 114, 825-828.

[11] Serjeant, G.R., Loy, L.L., Crowther, M., Hambleton, I.R. and Thame, M. (2004) Outcome of Pregnancy in Homozygous Sickle Cell Disease. Obstetrics \& Gynecology, 103, 1278-1285. http://dx.doi.org/10.1097/01.aog.0000127433.23611.54

[12] Carroli, G. and Bergel, E. (2004) Umbilical Vein Injection for Management of Retained Placenta. Cochrane Database of Systematic Reviews, No. 4, CD001337.

[13] Orji, E., Agwu, F., Loto, O. and Olaleye, O. (2008) A Randomized Comparative Study of Prophylactic Oxytocin versus Ergometrine in the Third Stage of Labour. International Journal of Gynecology and Obstetrics, 101, 129-132. http://dx.doi.org/10.1016/j.ijgo.2007.11.009

[14] Weeks, A.D., Alia, G., Vernon, G., Namayanja, A., Gosakan, R., Majeed, T., Hart, A., Jafri, H., Nardin, J., Carroli, G., Fairlie, F., Raashid, Y., Mirembe, F. and Alfirevic, Z. (2010) Umbilical Vein Oxytocin for the Treatment of Retained Placenta (Release Study): A Double Blind Randomised Controlled Trial. Lancet, 375, 141-147. http://dx.doi.org/10.1016/S0140-6736(09)61752-9

[15] Rogers, M.S., Yuen, P.M. and Wong, S. (2007) Avoiding Manual Removal of Placenta: Evaluation of Intraumbilical Vein Injection of Uterotonics Using the Pipingas Technique for Management of Adherent Placenta. Acta Obstetricia et Gynecologica Scandinavica, 86, 48-54. http://dx.doi.org/10.1080/00016340601088570

[16] Eifediyi, R.A., Eigbefoh, J.O., Isabu, P.A., Omorogbe, F.I., Ukponmwan, O.G. and Momoh, M. (2011) Retained Placenta: Still a Cause of Maternal Morbidity and Mortality in a Nigerian Semi-Urban Population. Sudan Journal of Medical Sciences, 6, 33-38.

[17] Akinola, O.I., Fawole, A.O., Adeyemi, A.S., Adegbola, O., Loto, O.M., Fabamwo, A.O., Alao, M.O. and Sotunsa, J.O. (2009) Active Management of Third Stage of Labour: Evidence versus Practice. Acta Obstetricia et Gynecologica Scandinavica, 88, 1252-1260. http://dx.doi.org/10.3109/00016340903280958

[18] Mutihir, J.T. and Utoo, B.T. (2011) Postpartum Maternal Morbidity in Jos, North-Central Nigeria. Nigerian Journal of Clinical Practice, 14, 38-42. http://dx.doi.org/10.4103/1119-3077.79238

[19] Etuk, S.J. and Ekanem, A.D. (2001) Sociodemographic and Reproductive Characteristics of Women Who Default from Orthodox Obstetric Care in Calabar, Nig. International Journal of Gynecology and Obstetrics, 73, 57-60. http://dx.doi.org/10.1016/S0020-7292(00)00386-6

[20] Chien, P.F.W. (2007) Third Stage of Labour and Abnormalities. In: Edmonds, K., Ed., Dewhurst's Textbook of Obstetrics and Gynaecology for Postgraduates, 6th Edition, 330-341.

[21] Njoku, C.O., Emechebe, C.I., Ekabua, J.E., Agbarakwe, H. and Abeshi, S. (2014) Utilisation and Discontinuation of Contraceptive Methods: The University of Calabar Teaching Hospital (UCTH) Experience. Global Journal of Medicine and Public Health, 3, 5.

[22] Soltan, M.H. and Khashoggi, T. (1997) Retained Placenta and Associated Risk Factors. Journal of Obstetrics and Gynaecology, 17, 245-247. http://dx.doi.org/10.1080/01443619750113159

[23] Schenker, J.R. and Margalioth, E.J. (2002) Intrauterine Adhesions: An Updated Appraisal. Fertility and Sterility, 37, 593-610.

[24] Hall, M.H., Halliwell, R. and Carr, H.R. (1985) Concomitant and Repeated Happening of Complications of Third Stage of Labour. British Journal of Obstetrics and Gynaecology, 92, 732-738.

http://dx.doi.org/10.1111/j.1471-0528.1985.tb01456.x 
[25] Tandberg, A., Albrechsten, S. and Iversen, O.E. (1999) Manual Removal of Placenta. Incidence and Clinical Significance. Acta Obstetricia et Gynecologica Scandinavica, 78, 33-36.

[26] Harrison, K.A. (1985) Childbearing, Health and Social Priorities: Survey of 22,774 Consecutive Hospital Births in Zaria, Northern Nigeria. British Journal of Obstetrics and Gynaecology, 92, 100-115. 